Article

\title{
Odor Characteristics and Concentration of Malodorous Chemical Compounds Emitted from a Combined Sewer System in Korea
}

\author{
Sangjin Park \\ School of Railroad Construction \& Environmental Engineering, Woo Song University, Daejeon 34606, Korea; \\ sjpark9731@daum.net
}

Received: 24 April 2020; Accepted: 16 June 2020; Published: 22 June 2020

\begin{abstract}
Objectives: This study was carried out to investigate the characteristics of odors emitted from a combined sewer for the abatement of combined sewer odor. (2) Methods: The odor samples emitted from the combined sewer were collected at 14 sites, and the concentrations of 13 malodorous chemicals were determined by the instrumental analysis such as gas chromatography. To understand the sensory characteristic of the combined sewer odor, the on-site odor intensity (OOI) was evaluated by the direct sensory method using the human olfactory sensitivity of panelists with a normal sense of smell. The primary odor-causing compounds with high contribution were evaluated based on the converted odor concentration (COC), which was calculated by using the compound concentration and threshold limit value. Since the direct sensory method requires a lot of manpower and time, the converted odor intensity method (COI) calculated by the malodorous compound concentration was reviewed and compared with other cases. (3) Results: As a result of the instrumental analysis, four compounds which were higher than other compounds, showed an average of $325 \mathrm{ppb}$ for $\mathrm{H}_{2} \mathrm{~S}, 121 \mathrm{ppb}$ for $\mathrm{NH}_{3}, 102 \mathrm{ppb}$ for $\mathrm{CH}_{3} \mathrm{SH}$, and $108 \mathrm{ppb}$ for toluene. The rest of the compounds appeared low, below $60 \mathrm{ppb}$. Based on the result of evaluating the $\mathrm{COC}$, three compounds which are $\mathrm{H}_{2} \mathrm{~S}, \mathrm{CH}_{3} \mathrm{SH}$, and $\left(\mathrm{CH}_{3}\right)_{3} \mathrm{~N}$ appeared to be compounds with a high contribution to combined sewer odor. Especially, it was estimated that $\mathrm{H}_{2} \mathrm{~S}$ was the main odor-causing compound in this study. The on-site odor intensity of the combined sewer as judged by 5 panelists appeared to be 2.8 degrees on average, the same as COI. The correlation between the odor intensity and the $\mathrm{H}_{2} \mathrm{~S}$ concentration in the combined sewer showed as the following equation: COI, degree $=1.0757 \times \log \left(\mathrm{H}_{2} \mathrm{~S}\right.$ conc., $\left.\mathrm{ppb}\right)+0.3696$. (4) Conclusions: In Korea, the odor emission standard in the atmosphere including sewer odor has adopted $20 \mathrm{ppb}$ for $\mathrm{H}_{2} \mathrm{~S}$, and less than 2 degrees for odor intensity in the non-industrial area. However, since the mean observed odor intensity was 2.8 degrees and the concentration of $\mathrm{H}_{2} \mathrm{~S}$ was also $325 \mathrm{ppb}$ on average in this study, it was concluded that countermeasures should be prepared to reduce the complaints due to combined sewer odor in residential areas.
\end{abstract}

Keywords: combined sewer odor; instrumental malodorous compounds analysis; olfactometry; malodorous compounds concentration; odor intensity; odor concentration

\section{Introduction}

Sewers are used to transport and treat water pollutants in domestic sewage and industrial wastewater to sewage treatment plants to improve river environment and preserve water quality. However, malodorous gas mixtures are generated from sewerage facilities such as manholes and catch basins, which can adversely affect the living environment and human health [1]. 
In general, some inorganic compounds such as hydrogen sulfide $\left(\mathrm{H}_{2} \mathrm{~S}\right)$, ammonia $\left(\mathrm{NH}_{3}\right)$ and some volatile organic compounds are known as representative malodorous substances emitted from sewers [2-5]. In particular, sulfur-based compounds such as $\mathrm{H}_{2} \mathrm{~S}$ are not only very easily detected at very low concentrations of $0.4 \mathrm{ppb}$ but are also highly corrosive and damage sewerage facilities, and are known to have a harmful effect on humans due to toxicity after prolonged exposure. Therefore, various techniques have been studied to remove malodorous compounds emitted from sewers such as $\mathrm{H}_{2} \mathrm{~S}[6-9]$.

However, most of these studies have been conducted in the separated sewer system or the pressure sewer pipes. Even though a separated sewer system has been installed in the newly developed area, most of the old cities still have the combined sewer system in Korea. Sewerage supplied rate based on sewer length in Korea is about $81.8 \%$ in 2018 , and $43,826 \mathrm{~km}, 28 \%$ of the total sewer length $(156,257 \mathrm{~km})$ has been constructed from a combined sewer system. In particular, Seoul metropolitan city, which has been the capital of Korea since 1329 AD with 9.73 million inhabitants, has a combined sewer system of $9545 \mathrm{~km}$, which is $89 \%$ of the city's sewer [10].

Unlike the separated sewer system which installs the storm sewer and sanitary sewer separately, the combined sewer system uses only one pipe to drain storm water and sewage simultaneously. As the combined sewer has a big dimeter and low flow velocity in a sewer, a large amount of organic matter in sewage is likely to settle down on the bottom of the sewer and is the cause behind generating a malodor. Sewer odors, especially malodorous gas emitted from the combined sewer have become a major social problem in Korea [11].

In Korea, in order to solve the odor problem of increasing social complaints, the Odor Prevention Law was enacted in 2004, and a number of projects have been carried out to reduce odors at workplaces in industrial complexes and odors from sewerage facilities in living environments.

Recently, many research projects were underway to reduce sewer odor in Korea. In 2010, Gangnam district and Seocho district of Seoul metropolitan city carried out the project to monitor sewer odor in real time around the G-20 Summit place, while injecting deodorants into the sewer to abate odor $[12,13]$. Recently, the Ministry of Environment of Korea invested 9 million U.S. dollars of research funds for 4 years to develop the abatement techniques of sewer odor using 4th industry technology [14].

Under these backgrounds, this study was conducted for the purpose of collecting basic data for justifying and reducing the odor problem of combined sewer odor. In order to understand the odor characteristics of the combined sewer, the concentration of inorganic compounds and volatile organic compounds in malodorous gas emitted from the combined sewer was investigated by an instrumental analysis. To investigate the main odor-causing compounds, the converted odor concentration (COC) was calculated by the malodorous compound concentration and its threshold limit value. Based on the results of the COC, the primary odorants which have a high contribution to the combined sewer odor was determined.

At the same time, to understand the sensory characteristic of the combined sewer odor, the odor intensity in the field was evaluated by the direct sensory method that is used to estimate the odor intensity using the olfactory sensitivity of five panelists, which was judged to be normal.

When evaluating the odor intensity, since the direct sensory method requires a lot of manpower and time, the converted odor intensity method (COI) was studied.

Based on the results of the correlation analysis between the $\mathrm{H}_{2} \mathrm{~S}$ concentration and the on-site odor intensity (OOI), the correlation equation between converted odor intensity (COI) and $\mathrm{H}_{2} \mathrm{~S}$ concentration was suggested. In addition, the COI calculated by the correlation equation was compared with the OOI by the panelists, and with the two cases of Japan and Korea. 


\section{Material and Methods}

\subsection{Outline of the Study Area and Sewer Odor Sampling Sites}

The target area, Cheonggye-cheon, is a $10.84 \mathrm{~km}$ long stream located in the center of the commercial area of Seoul metropolitan city. In 2005, the $5.84 \mathrm{~km}$ of stream section was developed as a shelter for citizens restoring it as a stream park with 22 bridges, trails, and a recovered ecosystem.

The Cheonggye-cheon drainage area which consists of a combined sewer system, has 278 combined sewers with trunk and branch lines, and most of the trunk lines are connected to the interceptor sewer installed on both sides of Cheonggye-cheon stream. However, the odor emitted from overflow chambers and outlets of the trunk sewer is drawing attention and leads to social complaints about the Cheonggye-cheon Park.

In this study, 14 trunk lines of the combined sewer connected to the Cheonggye-cheon stream were selected as the sampling site. Figure 1 illustrates the location of the study area and 14 sampling sites, and Figure 2 shows a photograph of the night view of the Cheonggye-cheon park at present [15] and a photo of the malodorous gas sampling in the inside of the Cheonggye-cheon interceptor before development of the park. The dotted line in Figure 1 shows the location of this study area. The circular dotted line in Figure 2 shows the odor sampling point in the Cheonggye-cheon Park.

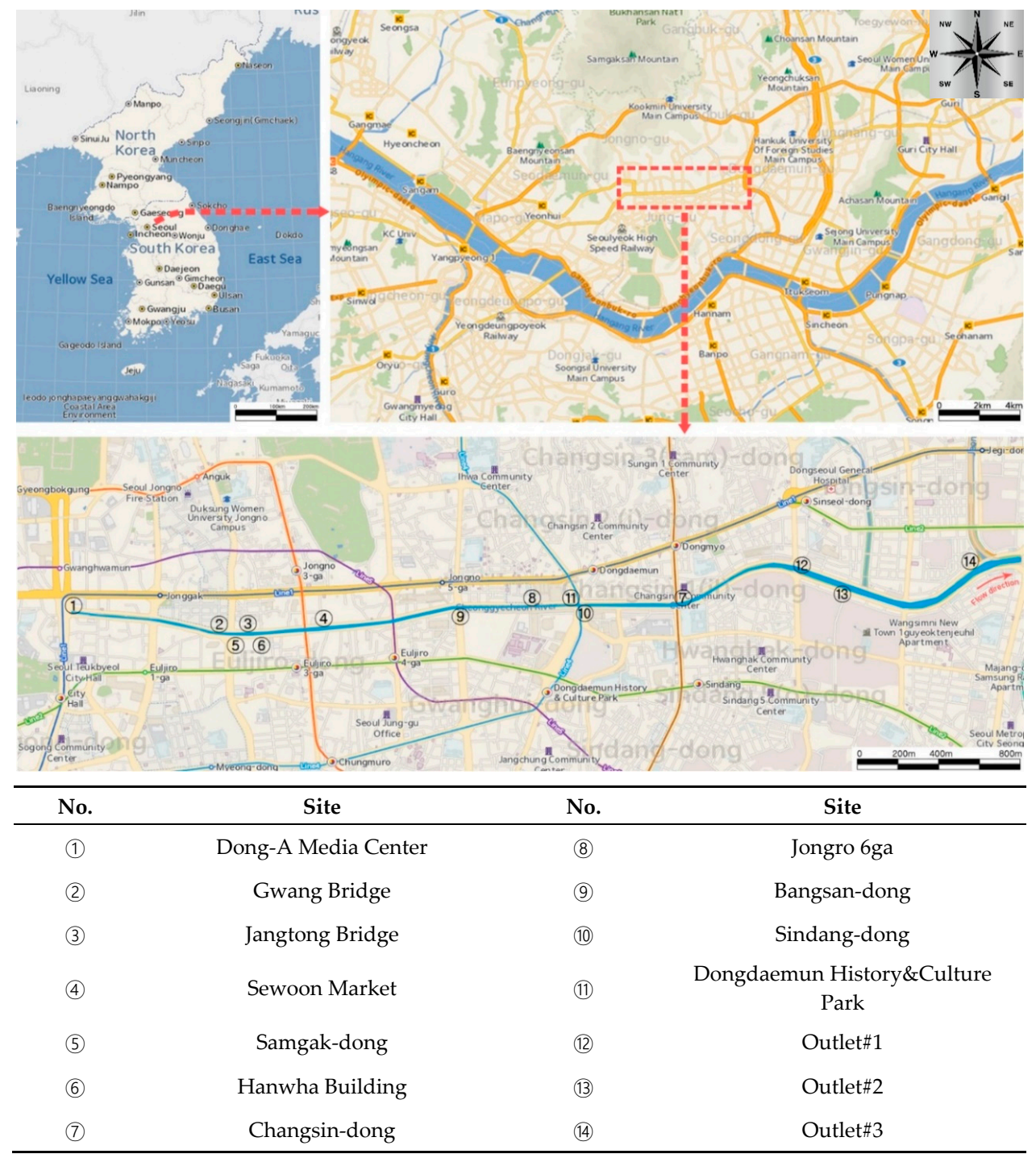

Figure 1. Location of the study area and the sampling sites in this study. 

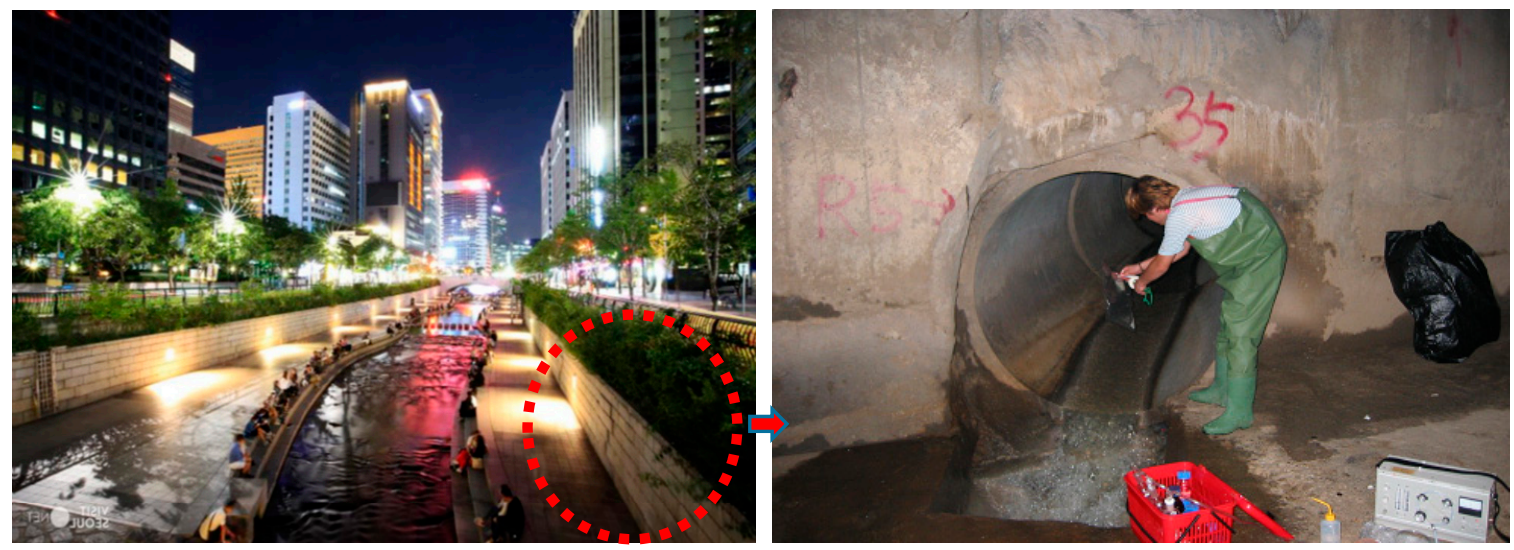

Figure 2. Night-view of Cheonggye-cheon park and a photograph of malodorous gas sampling at the inside of interceptor in this study.

\subsection{Determination of Target Malodorous Compounds and Analysis Methods}

\subsubsection{Determination and Analysis of Target Odorant Compounds}

In this study, a total of 13 chemical compounds, which are Hydrogen sulfide $\left(\mathrm{H}_{2} \mathrm{~S}\right)$, Methyl mercaptan (MM), Dimethyl sulfide (DMS), Dimethyl disulfide (DMDS), Ammonia $\left(\mathrm{NH}_{3}\right)$, Trimethylamine (TMA), Acetaldehyde, Benzene, Ethyl-benzene, toluene, $m, p$-Xylene, $o$-Xylene, and Styrene, were selected as the target odorants.

\subsubsection{Analysis of Target Malodorous Compounds}

The concentration of sulfur-containing compounds in the odor samples was measured using a Gas Chromatograph with Flame Photometric Detector (GC17A/FPD, Shimadzu Co., Kyoto, Japan) and glass packed column filled with $\beta, \beta^{\prime}$-oxidropionitriebo 60 80 mesh chromosorb w. A standard calibration curve was prepared using a standard gas (Kotte \& Zeller Co., Cypress CA, USA) of 47.8 ppm $_{\mathrm{v}}$ hydrogen sulfide, $45.7 \mathrm{ppm}_{\mathrm{v}}$ methyl mercaptan, $44.4 \mathrm{ppm}_{\mathrm{v}}$ dimethyl sulfide and $47.6 \mathrm{ppm}_{\mathrm{v}}$ dimethyl disulfide charged in high pressure nitrogen gas. Additionally, the standard calibration curve was corrected from time to time according to the GC condition. The operational condition of GC was set to $50 \mathrm{~mL}-\mathrm{N}_{2} / \mathrm{min}$ for carrier gas flow rate, $60 \mathrm{kpa}$ for gas pressure of $\mathrm{H}_{2}$, and temperature conditions of column $70{ }^{\circ} \mathrm{C}$, injector $150^{\circ} \mathrm{C}$, and detector $150^{\circ} \mathrm{C}$.

A Gas Chromatograph Mass Spectrometer (GCMS-QP5050A, Shimadzu Co., Japan) was used to analyze odorants of volatile organic compounds, while ammonia was analyzed by an UV-spectrophotometer at a $640 \mathrm{~nm}$ wave length and tolune by a Gas Chromatograph with Flame Ionization Detector (GC14B/FID, Shimadzu Co., Japan) with DB-FFAP(0.53 mm(I.D) $\times 30 \mathrm{~m}$, film thickness $1 \mu \mathrm{m}$ ) column.

Tables 1 and 2 show the analysis conditions of GC17A/FPD to analyze sulfur compounds and GCMS to analyze volatile organic compounds used in this study individually. Analytical methods for odorous substances in the mixed gas using instruments such like GC can be referred to in various materials with the U.S. EPA Method and ASTM-international for air pollutants analysis, including the Korean standard method for odor estimation [16-18].

Table 1. Analysis condition of GC17A/FPD used in this study.

\begin{tabular}{ll}
\hline Model & GC-17A(Shimadzu, Kyoto, Japan) \\
\hline Detector & Flame Photometric Detector \\
Oven/Injection/Detector Temp. & $80{ }^{\circ} \mathrm{C} / 150^{\circ} \mathrm{C} / 150^{\circ} \mathrm{C}$ \\
Column & Packed Column $(2.6 \mathrm{~mm}(\mathrm{I} . \mathrm{D}) \times 3 \mathrm{~m})$ \\
\hline
\end{tabular}


Table 1. Cont.

\begin{tabular}{ll}
\hline Model & GC-17A(Shimadzu, Kyoto, Japan) \\
\hline Column Material & $\beta, \beta^{\prime}$-oxidropionitriebo 60 80 mesh chromosorb w \\
Carrier Gas Flow Rate & $50 \mathrm{~mL} / \mathrm{min}$ \\
$\mathrm{H}_{2}$ Gas Pressure & $60 \mathrm{kpa}$ \\
Carrier Gas & $\mathrm{N}_{2}$ \\
& $\mathrm{H}_{2} \mathrm{~S} 47.8 \mathrm{ppm}_{\mathrm{v}}, \mathrm{CH}_{3} \mathrm{SH} 45.7 \mathrm{ppm}_{\mathrm{v}}$, \\
Standard Gas & $\left(\mathrm{CH}_{3}\right)_{2} \mathrm{~S} 44.4 \mathrm{ppm}_{\mathrm{v}},\left(\mathrm{CH}_{3}\right)_{2} \mathrm{~S}_{2} 47.6 \mathrm{ppm}$ \\
& $\left(\mathrm{Kotte}_{\mathrm{v}}\right.$ Zeller Co., Cypress CA, USA) \\
\hline
\end{tabular}

Table 2. Analysis condition of GCMS used in this study.

\begin{tabular}{ll}
\hline Model & GCMS-QP5050A(Shimadzu, Kyoto, Japan) \\
\hline & Aerotrap Desorber Techmar Dohrmann 6000 \\
& Adsorbent Tube Tekmar Tube \#14-1677-203 \\
& Cabosieve S-III + Tenax TA \\
\hline Oven/Injection/Interface Temp. & $35^{\circ} \mathrm{C} / 100{ }^{\circ} \mathrm{C} / 270{ }^{\circ} \mathrm{C}$ \\
Column & Capillary column $(60 \mathrm{~m} \times 0.32 \mathrm{~mm}(\mathrm{I} . \mathrm{D}) \times 0.25 \mu \mathrm{m}(\mathrm{df}))$ \\
Pressure & $30 \mathrm{kpa}$ \\
Temp. program & $35^{\circ} \mathrm{C}(4 \mathrm{~min}) \rightarrow 5^{\circ} \mathrm{C} / \mathrm{min} \rightarrow 85^{\circ} \mathrm{C}(2 \mathrm{~min})$ \\
Mass range & $\rightarrow 7^{\circ} \mathrm{C} / \mathrm{min} \rightarrow 250^{\circ} \mathrm{C}(10 \mathrm{~min})$ \\
Scan interval & $34 \sim 300$ \\
Detector volts & $0.5 \mathrm{~s}$ \\
Carrier gas & $1.5 \mathrm{kV}$ \\
\hline
\end{tabular}

\subsection{Evaluation of On-Site Odor Intensity Using a Panelist's Olfactory Test Method}

The on-site odor intensity of the combined sewer was evaluated in the field using a five panelist's olfactory sensitivity. Table 3 shows the odor intensity grade estimated by the human nose in the field. The odor intensity is divided into six stages from 0 degrees to 5 degrees according to the odor intensity perceived in the field by five panelists whose sensory systems were determined to be normal.

Table 3. Classification of odor intensity by the human nose.

\begin{tabular}{ccc}
\hline Degrees & Intensity & Properties \\
\hline 0 & None & People cannot feel an odorous smell with a normal sense of smell \\
1 & Threshold & People smell something but cannot recognize the type of smell \\
2 & Moderate & People smell something and can recognize the type of smell \\
3 & Strong & People easily smell something strongly like a cresol smell in hospitals \\
4 & Very Strong & People strongly smell something like a conventional rest room \\
5 & Over Strong & People strongly smell something and gag or hold their breath \\
\hline
\end{tabular}

The average of five panelists is determined on the represented odor intensity of the site. Figure 3 shows the procedure of panelist selection for an olfactometry odor estimation in Korea.

\subsection{Evaluation of Odor Concentration Using the Odorant Compounds Concentration and Threshold Limit Value}

Odor intensity mainly indicates the strength of odor detected by a human nose at the site, but odor concentration is mainly used to evaluate the concentration of mixed odor (or odorous mixtures) emitted from the site. 


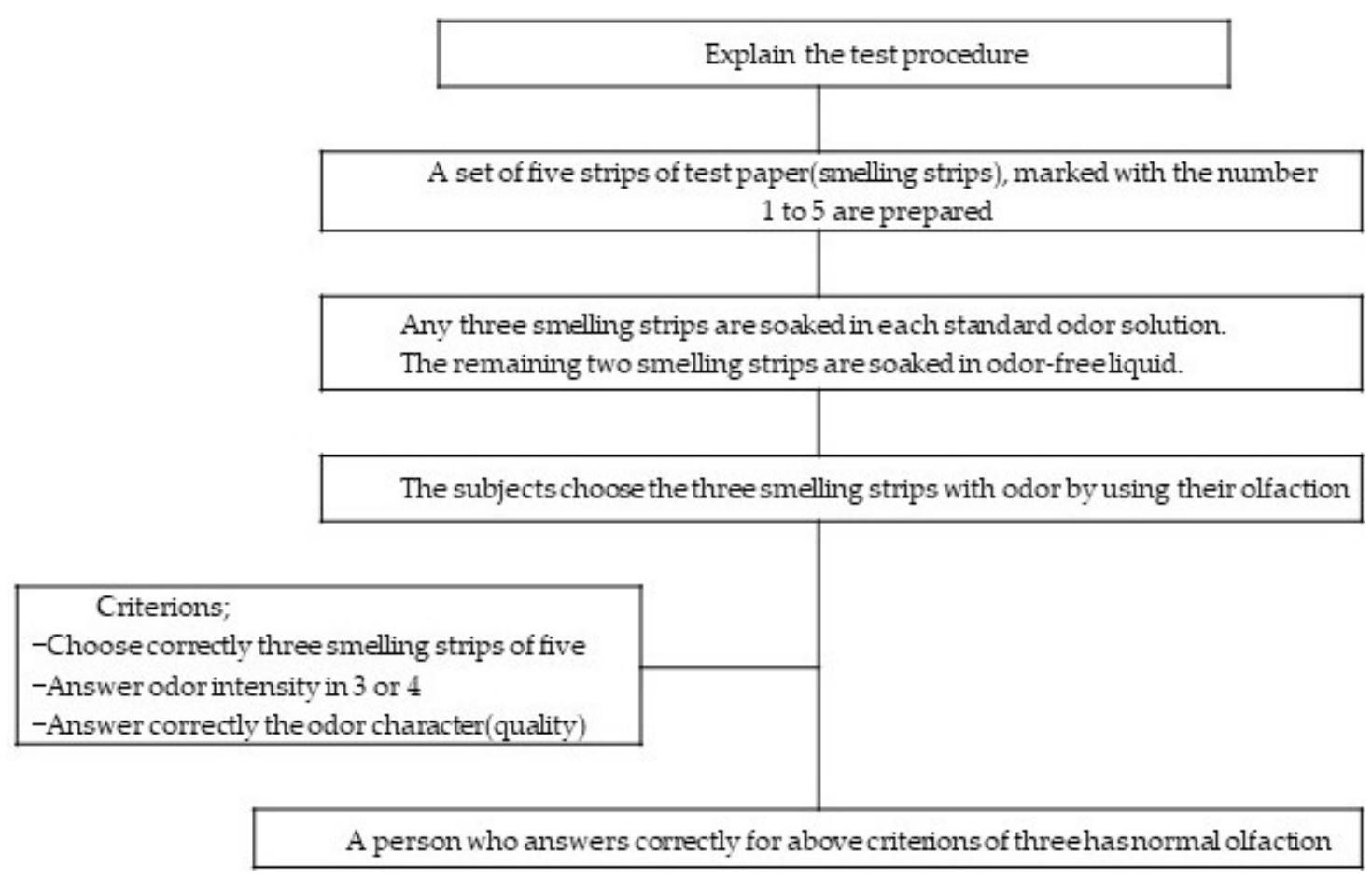

Figure 3. Procedure of panelist selection for a human odor estimation in Korea.

In general, the odor concentration is evaluated using the amount of dilution air flow rates injected by using a dynamic olfactometer or an odor bag until the odor is not detected by a human nose. However, this method has a drawback in that it requires a lot of experimental expense with the evaluation time. Additionally, odor concentration can be theoretically calculated by using the compound concentration in the odor gas and the threshold limit value of the compound as shown in Equation (1) $[19,20]$.

$$
\mathrm{COC}=\mathrm{MCC} / \mathrm{TLV}
$$

where

COC: Converted Odor Concentration

MCC: Malodorous Compounds Concentration (ppm or ppb)

TLV: Threshold Limit Value (ppm or ppb)

Table 4 shows the threshold limit values of the malodorous compounds investigated in this study. The threshold limit value data of Koreans was used for the calculation of COC in this study. For compounds with no Korean data, Japanese data were used [21-23].

Table 4. Threshold limit values of the target malodorous compounds in this study.

\begin{tabular}{lccc}
\hline Compound (Unit: ppb) & Korea [21] & Japan [22] & USA [23] \\
\hline Hydrogen sulfide $\left(\mathrm{H}_{2} \mathrm{~S}\right)$ & 0.4 & 0.41 & 0.47 \\
Methyl mercaptan (MM) & 0.3 & 0.07 & 2.1 \\
Dimethyl sulfide (DMS) & 3.1 & 3 & 1 \\
Dimethyl disulfide (DMDS) & 2.2 & 2.2 & 1 \\
Ammonia ( $\left.\mathrm{NH}_{3}\right)$ & 2890 & 1500 & 46,800 \\
Trimethylamine (TMA) & 0.2 & 0.032 & 0.21 \\
Acetaldehyde & 2.6 & 1.5 & 210 \\
Benzene & & 2700 & 4680 \\
Ethyl-benzene & & 170 & \\
\hline
\end{tabular}


Table 4. Cont.

\begin{tabular}{lccc}
\hline Compound (Unit: $\mathbf{p p b})$ & Korea [21] & Japan [22] & USA [23] \\
\hline Toluene & 1221 & 330 & 2140 \\
m,p-Xylene & 62.8 & 49.5 & 470 \\
$o-X y l e n e$ & & 380 & \\
Styrene & 70 & 35 & 47 \\
\hline
\end{tabular}

\section{Results}

\subsection{Concentration of Target Malodorous Compounds Emitted from Sewage Odor}

Table 5 shows the results of the target compounds concentration in malodorous gas emitted from the combined sewer. As shown in Table 5, $\mathrm{H}_{2} \mathrm{~S}$ was $325 \mathrm{ppb}$ on average, $\mathrm{NH}_{3} 121$ ppb on average, MM $102 \mathrm{ppb}$ on average, and toluene was $108 \mathrm{ppb}$ on average. The rest of the compounds appeared low, below $60 \mathrm{ppb}$. In addition, when looking at the distribution of compound concentration, statistically, the coefficient of variation of most compounds was about 1 or higher. However, the coefficient of variation of $\mathrm{H}_{2} \mathrm{~S}$ was 0.74 , indicating that the variation in measured values was much less than that of other compounds. Therefore, it is considered that $\mathrm{H}_{2} \mathrm{~S}$ is suitable for the indicator compounds of sewer odor among the 13 compounds investigated in this study, considering the contribution to the odor with the stability of variation and the magnitude of concentration in the measured value.

Meanwhile, the concentration of sulfur-containing malodorous compounds at three sites which were Dong-A Media Center of site no. 1, Dongdaemun History \& Culture Park of site no. 11, and outfall \#2 of site no. 13 were extremely higher than other sites. It was thought to be due to the influence of other sewerage facilities such as the septic tanks of building or house connections that are directly connected to the combined sewer. In addition, a free drop of sewage into the overflow chambers from the trunk sewer was also affected to emit sewer odor at the site.

\subsection{Observed Odor Intensity(OOI) by On-Site Olfactory Test Method}

Table 6 shows the results of on-site odor intensity surveys by five panelists for the combined sewer odor, and the on-site odor intensity measured at 14 sites was 2.8 degrees on average as shown in Table 6. However, site no. 6 of Hanwha-building was found to be much lower than other points, due to the large amount of external air injected into the sewer due to the sewerage repair work at the time of the investigation, and the inner odor of the sewer was diluted.

Since the Odor Prevention Law in Korea sets the odor intensity to 2 degrees or less for the odor level in air quality of residential areas, it appeared that the odor generated in the combined sewer needs to be reduced. 
Table 5. Concentration of odorant compounds in malodorous gas emitted from the combined sewer (unit: ppb).

\begin{tabular}{|c|c|c|c|c|c|c|c|c|c|c|c|c|c|c|}
\hline \multicolumn{2}{|r|}{ Site } & \multirow{2}{*}{$\begin{array}{r}\mathbf{H}_{2} \mathbf{S} \\
858\end{array}$} & \multirow{2}{*}{$\begin{array}{c}\text { MM } \\
69\end{array}$} & \multirow{2}{*}{$\begin{array}{c}\text { DMS } \\
48\end{array}$} & \multirow{2}{*}{$\begin{array}{c}\text { DMDS } \\
\text { ND. }\end{array}$} & \multirow{2}{*}{$\begin{array}{l}\mathbf{N H}_{3} \\
\mathrm{~N} . \mathrm{D}\end{array}$} & \multirow{2}{*}{$\begin{array}{c}\text { TMA } \\
43\end{array}$} & \multirow{2}{*}{$\begin{array}{c}\text { Acetaldehyde } \\
34\end{array}$} & \multirow{2}{*}{$\begin{array}{c}\text { Benzene } \\
0.53\end{array}$} & \multirow{2}{*}{$\begin{array}{c}\text { Ethyl-Benzene } \\
82\end{array}$} & \multirow{2}{*}{$\begin{array}{c}\text { Toluene } \\
54\end{array}$} & \multirow{2}{*}{$\begin{array}{c}\text { m,p-Xylene } \\
4.2\end{array}$} & \multirow{2}{*}{$\begin{array}{c}o \text {-Xylene } \\
\text { N.D. }\end{array}$} & \multirow{2}{*}{$\begin{array}{c}\text { Styrene } \\
31\end{array}$} \\
\hline 1 & Dong-A Media Center & & & & & & & & & & & & & \\
\hline 2 & Gwang Bridge & 256 & 35 & 25 & N.D. & 242 & 7.9 & 25 & 0.29 & 20 & 58 & 1.8 & 1.8 & 2.9 \\
\hline 3 & Jangtong Bridge & 175 & 17 & 13 & N.D. & 356 & N.D & 17 & N.D. & 76 & 45 & 5.2 & 22 & N.D. \\
\hline 4 & Sewoon Shopping Street & 42 & 10 & 12 & 8.1 & 274 & N.D & 12 & 0.9 & 444 & 179 & 109 & 107 & N.D. \\
\hline 5 & Samgak-dong & 454 & 51 & 26 & N.D. & 310 & N.D & 36 & 0.29 & 116 & 61 & 15 & 62 & N.D. \\
\hline 6 & Hanwha Building & 2.4 & N.D. & N.D. & N.D. & N.D. & N.D & 6.3 & 8.5 & 14 & 20 & 1.8 & 6 & N.D. \\
\hline 7 & Changsin-dong & 90 & 24 & 24 & 2.7 & $\operatorname{tr}$ & N.D. & N.D. & N.D. & 16 & 25 & 15 & 8.6 & 0.23 \\
\hline 8 & Jongro $6 \mathrm{ga}$ & 378 & 27 & 24 & N.D. & 448 & 87 & N.D. & N.D. & 9.3 & 21 & 15 & 13 & N.D. \\
\hline 9 & Bangsan-dong & 238 & 166 & 34 & N.D. & 60 & 70 & 13 & N.D. & 25 & 339 & 58 & 57 & N.D. \\
\hline 10 & Sindang-dong & 358 & N.D. & N.D. & N.D. & $\operatorname{tr}$ & 98 & N.D. & N.D. & 2.1 & 22 & 3.8 & 3.2 & 0.53 \\
\hline 11 & $\begin{array}{l}\text { Dongdaemun } \\
\text { Histrye-Culture Park }\end{array}$ & 668 & 554 & 167 & N.D. & $\operatorname{tr}$ & 163 & N.D. & 1.0 & 32 & 605 & 21 & 16 & N.D. \\
\hline 12 & $\begin{array}{l}\text { History\& } \\
\text { Outlet\#1 }\end{array}$ & 100 & 56 & 55 & N.D. & $\operatorname{tr}$ & N.D. & N.D. & N.D. & 5.9 & 25 & 9.4 & 11 & 0.28 \\
\hline 13 & Outlet\#2 & 589 & 86 & 83 & N.D. & $\operatorname{tr}$ & 70 & N.D. & 1.1 & 1.2 & 38 & 1.8 & 1.5 & 0.38 \\
\hline 14 & Outlet\#3 & 336 & 332 & 332 & N.D. & $\operatorname{tr}$ & 70 & N.D. & 0.5 & 3.5 & 20 & 6.4 & 6.6 & 0.56 \\
\hline & Average & 325 & 102 & 60 & 0.8 & 121 & 44 & 10 & 0.9 & 60 & 108 & 19 & 23 & 2.6 \\
\hline & Minimum & 2.4 & 10 & 12 & 2.7 & 60 & 7.9 & 6.3 & 0.29 & 1.2 & 20 & 1.8 & 1.5 & 0.23 \\
\hline & Maximum & 858 & 554 & 332 & 8.1 & 448 & 163 & 36 & 8.5 & 444 & 605 & 109 & 107 & 31 \\
\hline & Standard Deviation & 242 & 157 & 89 & 2.7 & 119 & 42 & 11 & 2.6 & 112 & 162 & 29 & 31 & 11 \\
\hline & Coefficient of Variation & 0.74 & 1.5 & 1.5 & 3.5 & 0.98 & 0.96 & 1.0 & 2.8 & 1.9 & 1.5 & 1.5 & 1.3 & 4.1 \\
\hline
\end{tabular}

N.D.: Not Detectable, tr: trace. 
Table 6. Observed on-site odor intensity by five panelists.

\begin{tabular}{|c|c|c|c|c|c|c|c|}
\hline & \multirow{2}{*}{ Site } & \multicolumn{6}{|c|}{ Observed On-Site Odor Intensity by 5 Panelists } \\
\hline & & A & B & $\mathrm{C}$ & $\mathbf{D}$ & $\mathbf{E}$ & Average \\
\hline 1 & Dong-A Media Center & 3 & 4 & 4 & 3 & 4 & 3.6 \\
\hline 2 & Gwang Bridge & 3 & 3 & 3 & 4 & 3 & 3.2 \\
\hline 3 & Jangtong Bridge & 2 & 2 & 2 & 2 & 2 & 2.0 \\
\hline 4 & Sewoon Shopping Street & 3 & 2 & 2 & 2 & 3 & 2.4 \\
\hline 5 & Samgak-dong & 3 & 3 & 3 & 3 & 3 & 3.0 \\
\hline 6 & Hanwha Building & 0 & 0 & 0 & 1 & 1 & 0.4 \\
\hline 7 & Changsin-dong & 3 & 4 & 3 & 3 & 3 & 3.2 \\
\hline 8 & Jongro 6ga & 3 & 2 & 3 & 2 & 3 & 2.6 \\
\hline 9 & Bangsan-dong & 4 & 3 & 4 & 4 & 4 & 3.8 \\
\hline 10 & Sindang-dong & 4 & 3 & 3 & 2 & 3 & 3.0 \\
\hline 11 & Dongdaemun History\&Culture Park & 4 & 4 & 4 & 4 & 4 & 4.0 \\
\hline 12 & Outlet\#1 & 3 & 3 & 2 & 3 & 3 & 2.8 \\
\hline 13 & Outlet\#2 & 3 & 3 & 2 & 2 & 3 & 2.6 \\
\hline \multirow[t]{6}{*}{14} & Outlet\#3 & 3 & 3 & 3 & 2 & 3 & 2.8 \\
\hline & Average & & & & & & 2.8 \\
\hline & Minimum & & & & & & 0.4 \\
\hline & Maximum & & & & & & 4.0 \\
\hline & Standard Deviation & & & & & & 0.85 \\
\hline & Coefficient of Variation & & & & & & 0.30 \\
\hline
\end{tabular}

\section{Discussion}

\subsection{Determination of Dominant Odorant Compounds in a Combined Sewer Odor}

The main malodorous compound in sewer odor was evaluated using the Converted Odor Concentration (COC) value. COC is calculated by using the threshold limit value in Table 4 and the odorant compound concentration in Table 5, as described in Section 2.4. Table 7 shows the COC of each compound at 14 sites, and the COC of the site was calculated as the sum of COC for each malodorous compound.

As shown in Table 7, COC for each site show different results depending on the site conditions, but it showed that the odor contribution of $\mathrm{H}_{2} \mathrm{~S}$ was the highest among the target compounds at all sites.

Ammonia and toluene, which had high concentrations of the compounds, were found to have very low effects as odor-causing substances. This is because the threshold limit values of the two compounds are very high, and the effect on the sense of smell of humans is not so high. However, even though the concentration of trimethylamine was very low, it turned out that the odor contribution of trimethylamine was very high due to an extremely low threshold limit value.

Overall, it is estimated that sulfur-based compounds occupy $83 \%$ of the sum of COC generated from all sites, while hydrogen sulfide appears to be the predominant odor-causing compound. 
Table 7. Converted odor concentration by odorant compounds in malodorous gas emitted from the combined sewer.

\begin{tabular}{|c|c|c|c|c|c|c|c|c|c|c|c|c|c|c|c|}
\hline & \multirow{2}{*}{$\begin{array}{c}\text { Sites } \\
\text { T.L.V.(Unit: ppb) }\end{array}$} & \multirow{2}{*}{$\begin{array}{c}\mathrm{H}_{2} \mathrm{~S} \\
0.4\end{array}$} & \multirow{2}{*}{$\begin{array}{c}\text { MM } \\
0.3 \\
\end{array}$} & \multirow{2}{*}{$\begin{array}{c}\text { DMS } \\
3.1 \\
\end{array}$} & \multirow{2}{*}{$\begin{array}{c}\text { DMDS } \\
2.2 \\
\end{array}$} & \multirow{2}{*}{$\begin{array}{l}\mathrm{NH}_{3} \\
2890\end{array}$} & \multirow{2}{*}{$\begin{array}{c}\text { TMA } \\
0.2\end{array}$} & \multirow{2}{*}{$\begin{array}{c}\text { Acetaldehyde } \\
2.6 \\
\end{array}$} & \multirow{2}{*}{$\begin{array}{c}\text { Benzene } \\
2700 \\
\end{array}$} & \multirow{2}{*}{$\begin{array}{c}\text { Ethyl-Benzene } \\
170 \\
\end{array}$} & \multirow{2}{*}{$\begin{array}{c}\text { Toluene } \\
1221 \\
\end{array}$} & \multirow{2}{*}{$\begin{array}{c}m, p \text {-Xylene } \\
62.8\end{array}$} & \multirow{2}{*}{$\begin{array}{c}o \text {-Xylene } \\
380\end{array}$} & \multirow{2}{*}{$\begin{array}{c}\text { Styrene } \\
70 \\
\end{array}$} & \multirow{2}{*}{$\begin{array}{l}\text { COC } \\
\text { Sum }\end{array}$} \\
\hline & & & & & & & & & & & & & & & \\
\hline 1 & Dong-A Media Center & 2144 & 231 & 15 & & & 214 & 13 & 0.0002 & 0.48 & 0.044 & 0.066 & & 0.44 & 2619 \\
\hline 2 & Ğwang Bridge & 641 & 117 & 8.1 & & 0.1 & 40 & 9.8 & 0.0001 & 0.11 & 0.047 & 0.029 & 0.0046 & 0.042 & 815 \\
\hline 3 & Jangtong Bridge & 437 & 58 & 4.0 & & 0.1 & & 6.5 & & 0.44 & 0.037 & 0.083 & 0.059 & & 507 \\
\hline 4 & $\begin{array}{l}\text { Sewoon Shopping } \\
\text { Street }\end{array}$ & 104 & 34 & 3.8 & 3.7 & 0.1 & & 4.6 & 0.0003 & 2.6 & 0.15 & 1.7 & 0.28 & & 154 \\
\hline 5 & Samgak-dong & 1136 & 171 & 8.3 & & 0.1 & & 14 & 0.0001 & 0.68 & 0.050 & 0.23 & 0.16 & & 1330 \\
\hline 6 & Hanwha Building & 5.9 & & & & & & 2.4 & 0.0031 & 0.080 & 0.017 & 0.028 & 0.016 & & 8.5 \\
\hline 7 & Changsin-dong & 225 & 80 & 7.7 & 1.2 & & & & & 0.068 & 0.021 & 0.24 & 0.023 & 0.0032 & 314 \\
\hline 8 & Jongro 6ga & 945 & 90 & 7.8 & & 0.2 & 438 & & & 0.055 & 0.017 & 0.25 & 0.034 & & 1481 \\
\hline 9 & Bangsan-dong & 595 & 555 & 11 & & 0.0 & 350 & 5.2 & & 0.15 & 0.28 & 0.93 & 0.15 & & 1517 \\
\hline 10 & Sindang-dong & 895 & & & & & 490 & & & 0.012 & 0.018 & 0.060 & 0.0085 & 0.0076 & 1385 \\
\hline 11 & $\begin{array}{c}\text { Dongdaemun History } \\
\text { \& Culture Park }\end{array}$ & 1671 & 1847 & 54 & & & 817 & & 0.0004 & 0.19 & 0.50 & 0.34 & 0.043 & & 4389 \\
\hline 12 & Outlet\#1 & 249 & 186 & 18 & & & & & & 0.035 & 0.021 & 0.15 & 0.028 & 0.0040 & 453 \\
\hline 13 & Outlet\#2 & 1474 & 287 & 27 & & & 350 & & 0.0004 & 0.0071 & 0.031 & 0.029 & 0.0039 & 0.0054 & 2138 \\
\hline 14 & Outlet\#3 & 840 & 1106 & 107 & & & 350 & & 0.0002 & 0.021 & 0.016 & 0.10 & 0.017 & 0.0080 & 2404 \\
\hline & COC sum & 11,361 & 4761 & 272 & 4.9 & 0.6 & 3047 & 55.7 & 0.0 & 4.9 & 1.2 & 4.3 & 0.8 & 0.5 & 19,513 \\
\hline & (percentage) & $58 \%$ & $24 \%$ & $1 \%$ & $0.025 \%$ & $0.003 \%$ & $16 \%$ & $0.285 \%$ & $0.00002 \%$ & $0.025 \%$ & $0.006 \%$ & $0.022 \%$ & $0.004 \%$ & $0.003 \%$ & $100 \%$ \\
\hline
\end{tabular}




\subsection{Correlation between On-Site Observed Odor Intensity and $\mathrm{H}_{2} \mathrm{~S}$ Concentration in a Combined Sewer Odor}

In general, a variety of methods are used to measure odors such as instrument analyzers like gas chromatographs, sensory devices like dynamic olfactometer, odor sensors or gas detection tubes. Additionally, new techniques for accurately evaluating odors have still been continuously developed [24-33].

In Korea, two methodologies have been used for odor evaluation. The one, called "Air Dilution Sensory Method", is used to estimate odor concentration of malodorous gas mixtures using human olfactory sensitivity, and the other is to analyze the concentration of malodorous chemical compounds in the mixed gas using instruments such as a gas chromatograph.

The method of using a human nose is a good way to understand the popular complaints of residents due to sewer odor, but there is a difference in the sensitivity of smell of the individual and it has a limitation in quantitative measurement. In addition, this method has a drawback that a high analysis cost such as labor costs and official trip expenses is required, since more than five panelists should go to the field to evaluate on-site odor intensity. On the other hand, an instrumental analysis method for measuring the concentration of a malodorous compound has the advantage of being capable of quantitative measurement and high reliability in the analysis results.

In this study, in order to supplement the limitations of an olfactometry, an alternative methodology was conducted to calculate the converted odor intensity (COI) using instrumental analysis results.

According to Weber-Fechner's law [34], [there is a logarithmic relationship between the odor intensity and the compound concentration, and the correlation equation between the odor intensity and the compound concentration can be expressed in Equation (2). The COI of the sewer odor was calculated by substituting the compound concentration into the correlation equation which is derived from the compound concentration and the observed odor intensity.

$$
\mathrm{COI}=\mathrm{a} \times \log (\mathrm{MCC})+\mathrm{b}
$$

where,

COI : Converted Odor Intensity

1. MCC: Malodorous Compounds Concentration

2. a, b: Coefficient for the malodorous compounds

In this study, as mentioned in Section $4.1, \mathrm{H}_{2} \mathrm{~S}$ is the representative malodorous compound in the combined sewer odor. Therefore, the concentration of $\mathrm{H}_{2} \mathrm{~S}$ was used as the malodorous compound concentration to be inputted into Equation (2). In order to evaluate the effectiveness of the COI method, the results of COI derived from this study were compared with the results of OOI estimated in the field [18]. Table 8 shows the correlation equation between the on-site observed odor intensity shown in Table 6 and the $\mathrm{H}_{2} \mathrm{~S}$ concentration in Table 5. Figure 4 illustrates the results of correlation analysis between odor intensity and $\mathrm{H}_{2} \mathrm{~S}$ concentration using the data in Table 8 .

Table 8. Calculated odor intensity obtained by correlation equation between observed on-site odor intensity and $\mathrm{H}_{2} \mathrm{~S}$ concentration in mixed odor.

\begin{tabular}{llccc}
\hline & \multicolumn{1}{c}{ Site } & $\mathbf{H}_{\mathbf{2}} \mathbf{S}$ & $\mathbf{L o g}\left(\mathbf{H}_{\mathbf{2}} \mathbf{S}\right)$ & OOI \\
\hline 1 & Dong-A Media Center & 858 & 2.93 & 3.6 \\
2 & Gwang Bridge & 256 & 2.41 & 3.2 \\
3 & Jangtong Bridge & 175 & 2.24 & 2.0 \\
4 & Sewoon Shopping Street & 42 & 1.62 & 2.4 \\
5 & Samgak-dong & 454 & 2.66 & 3.0 \\
6 & Hanwha Building & 2.4 & 0.37 & 0.4 \\
7 & Changsin-dong & 90 & 1.95 & 3.2 \\
\hline
\end{tabular}


Table 8. Cont.

\begin{tabular}{|c|c|c|c|c|}
\hline \multicolumn{2}{|r|}{ Site } & \multirow{2}{*}{$\begin{array}{r}\mathbf{H}_{\mathbf{2}} \mathbf{S} \\
378\end{array}$} & \multirow{2}{*}{$\frac{\log \left(\mathbf{H}_{\mathbf{2}} \mathbf{S}\right)}{2.58}$} & \multirow{2}{*}{$\begin{array}{c}\text { OOI } \\
2.6\end{array}$} \\
\hline 8 & Jongro 6ga & & & \\
\hline 9 & Bangsan-dong & 238 & 2.38 & 3.8 \\
\hline 10 & Sindang-dong & 358 & 2.55 & 3.0 \\
\hline 11 & Dongdaemun History \& Culture Park & 668 & 2.83 & 4.0 \\
\hline 12 & Outlet\#1 & 100 & 2.00 & 2.8 \\
\hline 13 & Outlet\#2 & 589 & 2.77 & 2.6 \\
\hline 14 & Outlet\#3 & 336 & 2.53 & 2.8 \\
\hline & Average & 325 & 2.3 & 2.8 \\
\hline & Standard Deviation & 242 & 0.6 & 0.9 \\
\hline & Coefficient of Variation & 0.74 & 0.28 & 0.30 \\
\hline & Correlation Equation & \multicolumn{3}{|c|}{$\begin{array}{l}\mathrm{Y}=1.0757 \times \log (\mathrm{X})+0.3696 \\
\text { where, } \mathrm{Y}: \text { Calculated odor intensity, degree } \\
\mathrm{X}: \mathrm{H}_{2} \mathrm{~S} \text { conc., } \mathrm{ppb}\end{array}$} \\
\hline
\end{tabular}

Unit: ppb of $\mathrm{H}_{2} \mathrm{~S}$, degrees of OOI.

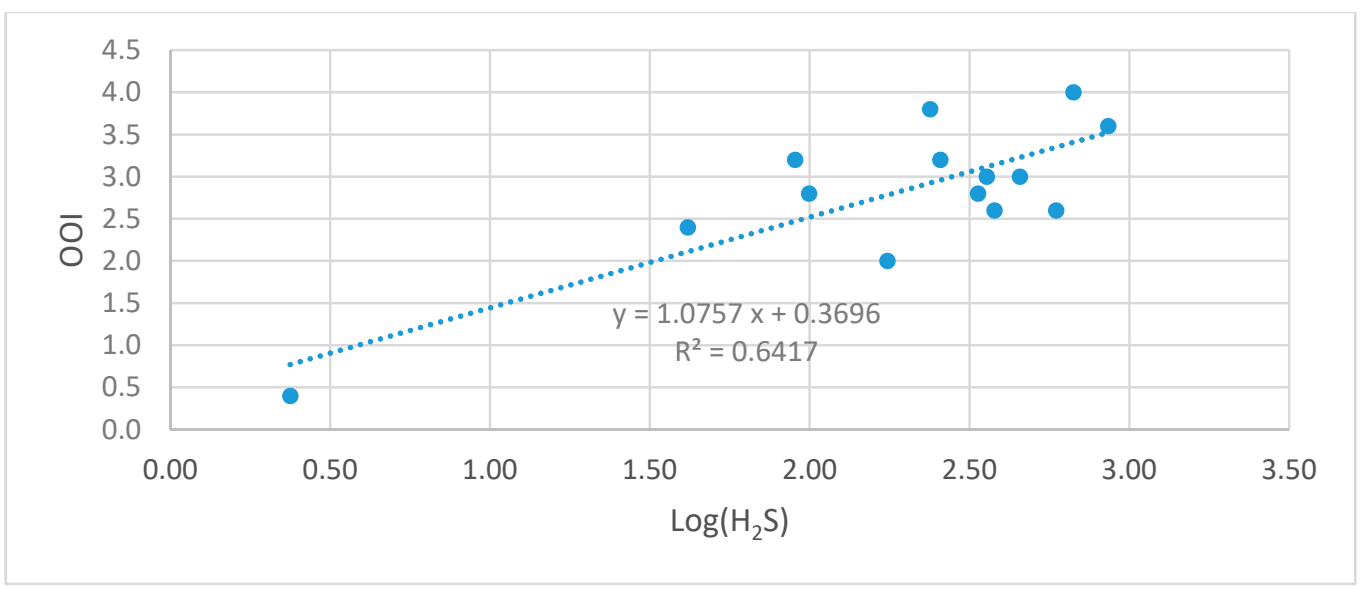

Figure 4. Correlation analysis between the observed odor intensity and the $\mathrm{H}_{2} \mathrm{~S}$ concentration of combined sewer odor in this study.

\subsection{Comparison of Other Studies about Correlation Equation between Odor Intensity and Compound Concentration}

In order to evaluate the reliability of the correlation equations derived from this study, it was compared with the correlation equations used in Korea [21] and Japan [35]. Table 9 shows the correlation equation between the odor intensity and the compound concentration derived from this study, including the correlation equation used in Korea and Japan. Table 10 show the COI evaluated using 3 correlation equations in Table 9 with the OOI measured in the field. Figure 5 illustrates the comparison of COI evaluated using three correlation equations in Table 9 with OOI measured in the field.

As can be seen from Table 10 and Figure 5, the COI calculated from the correlation equation of Korea and Japan was evaluated higher than the OOI at most of sites, while the average of COI calculated from the correlation equation derived in this study did not show a significant difference from the average value of OOI measured in the field. In addition, the coefficient of variation of COI was also 0.24 , which was lower than 0.3 of OOI. From these results, it is estimated that the COI method can obtain more stable results than the OOI method. However, it was thought that these results were due to the fact that the gas to be tested in this study was not a standard gas such as Korea's equation and Japan's equation, but an on-site malodorous gas emitted from a combined sewer.

Therefore, when measuring the odor intensity in order to understand the characteristics of the combined sewer odor, since the OOI method requires a lot of manpower and time, it was estimated that 
the COI method calculated by using the malodorous compound concentration can also be effectively used as the alternative methodology.

Table 9. Correlation equation between odor intensity and $\mathrm{H}_{2} \mathrm{~S}$ concentration.

\begin{tabular}{llll}
\hline & & \multicolumn{1}{c}{ Correlation Equation } & \multicolumn{1}{c}{ Sample } \\
\hline This study & & $\mathrm{COI}=1.0757 \times \log \left(\mathrm{H}_{2} \mathrm{~S}\right.$ Conc. of $\left.\mathrm{ppb}\right)+0.3696$ & Combined sewer odor \\
\hline \multirow{2}{*}{ Reference } & Equation of Korea [20] & $\mathrm{COI}=0.8815 \times \log \left(\mathrm{H}_{2} \mathrm{~S}\right.$ Conc. of ppm $)+4.0688$ & $\mathrm{H}_{2} \mathrm{~S}$ Standard gas \\
\cline { 2 - 5 } & Equation of Japan [34] & $\mathrm{COI}=0.95 \times \log \left(\mathrm{H}_{2} \mathrm{~S}\right.$ Conc. of ppm $)+4.14$ & $\mathrm{H}_{2}$ S Standard gas \\
\hline
\end{tabular}

Table 10. Comparison of observed odor intensity and three kinds of calculated odor intensity.

\begin{tabular}{llcccc}
\hline & Site & OOI & COI $_{\text {This Study }}$ & COI $_{\text {Korea }}$ & COI Japan $^{\text {COn }}$ \\
\hline 1 & Dong-A Media Center & 3.60 & 3.53 & 4.01 & 4.08 \\
2 & Gwang Bridge & 3.20 & 2.96 & 3.55 & 3.58 \\
3 & Jangtong Bridge & 2.00 & 2.78 & 3.40 & 3.42 \\
4 & Sewoon Shopping Street & 2.40 & 2.11 & 2.85 & 2.83 \\
5 & Samgak-dong & 3.00 & 3.23 & 3.77 & 3.81 \\
6 & Hanwha Building & 0.40 & 0.77 & 1.75 & 1.65 \\
7 & Changsin-dong & 3.20 & 2.47 & 3.15 & 3.15 \\
8 & Jongro 6ga & 2.60 & 3.14 & 3.70 & 3.74 \\
9 & Bangsan-dong & 3.80 & 2.93 & 3.52 & 3.55 \\
10 & Sindang-dong & 3.00 & 3.12 & 3.68 & 3.72 \\
11 & Dongdaemun History \& Culture Park & 4.00 & 3.41 & 3.91 & 3.97 \\
12 & Outlet\#1 & 2.80 & 2.52 & 3.19 & 3.19 \\
13 & Outlet\#2 & 2.60 & 3.35 & 3.87 & 3.92 \\
14 & Outlet\#3 & 2.80 & 3.09 & 3.65 & 3.69 \\
\hline & Average & 2.8 & 2.8 & 3.4 & 3.4 \\
\hline
\end{tabular}

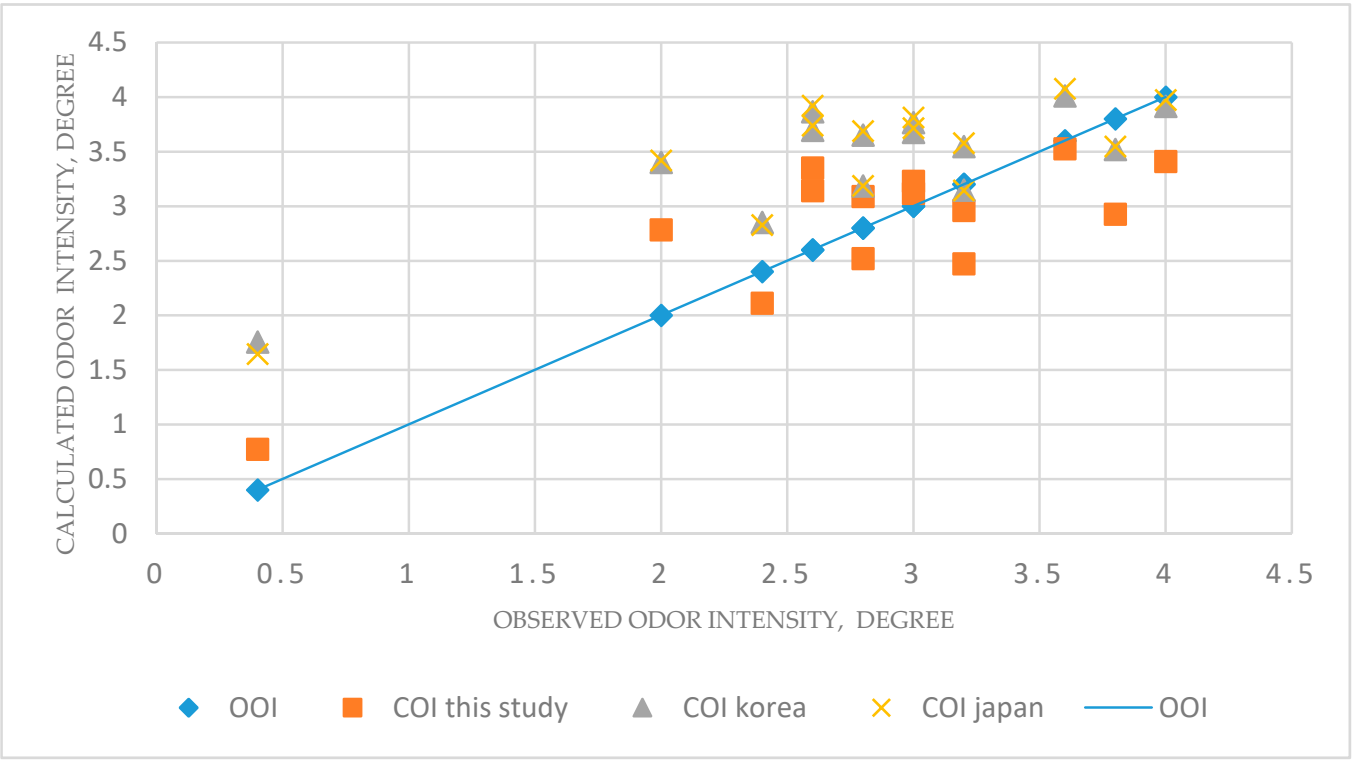

Figure 5. Comparison of observed odor intensity and three kinds of calculated odor intensity.

\section{Conclusions}

This study was carried out to investigate the odor characteristics of the combined sewer in order to collect a basic data for the abatement of the odor of the combined sewer odor. The concentration 
of 13 compounds among inorganic compounds and volatile organic compounds in malodorous gas emitted from the Cheonggyecheon combined sewer area in downtown Seoul city was analyzed. In addition, by using the converted odor concentration (COC) calculated using the threshold limit values, the main malodorous compounds with high contribution to odor among 13 target odorants were investigated and presented.

To understand the sensory characteristic of the combined sewer odor, the on-site odor intensity was evaluated by the direct sensory method, that is to estimate the odor intensity using the olfactory sensitivity of five panelists with a normal sense of smell. When measuring the odor intensity of the combined sewer odor, since the direct sensory method (OOI) requires a lot of manpower and time, the converted odor intensity method (COI) calculated by using the malodorous compound concentration were reviewed as the alternative and compared with other cases.

The results of this study are summarized as follows;

1. Among the 13 malodor substances investigated in this study, the inorganic malodor compounds had an average of $325 \mathrm{ppb}$ for $\mathrm{H}_{2} \mathrm{~S}, 121 \mathrm{ppb}$ for $\mathrm{NH}_{3}, 102 \mathrm{ppb}$ for $\mathrm{CH}_{3} \mathrm{SH}$, and toluene showed an average of $108 \mathrm{ppb}$ for volatile organic compounds, which was higher than other compounds. The rest of the compounds appeared low, below $60 \mathrm{ppb}$.

2. On the basis of the $\mathrm{COC}$ calculated by using the compound concentration and the threshold limit value, $\mathrm{H}_{2} \mathrm{~S}, \mathrm{CH}_{3} \mathrm{SH}$, and $\left(\mathrm{CH}_{3}\right)_{3} \mathrm{~N}$ turned out to be compounds with high contribution to combined sewer odor. Especially, $\mathrm{H}_{2} \mathrm{~S}$ was estimated to be the primary odor-causing compound, considering the contribution to the odor and the magnitude of compound concentration.

3. The on-site odor intensity estimated by 5 panelists at 14 sites of combined sewer was found to be 2.8 degrees on average. It showed that the odor emitted from the combined sewer needs to be reduced because the odor emission criteria of non-industrial areas in Korea are set to be less than 2.5 degrees of odor intensity.

4. As a result of the correlation analysis between the measured $\mathrm{H}_{2} \mathrm{~S}$ concentration and the observed odor intensity in this study, the correlation between the odor intensity and the compound concentration in the combined sewer appeared as the following equation: $\mathrm{COI}$, degrees $=1.0757$ $\times \log \left(\mathrm{H}_{2} \mathrm{~S}\right.$ conc., $\left.\mathrm{ppb}\right)+0.3696$.

5. Since the method of on-site odor intensity by the human nose requires a lot of manpower and time, it was estimated that the COI method using the malodorous compound concentration can also be effectively used to evaluate the odor intensity to understand the characteristics of the combined sewer odor, as the alternative of OOI.

Funding: This study was supported by the 2019 research fund of Woo Song University. I would like to show my gratitude to Odor and VOCs Research Center under Woo Song University Industry Academy Cooperation Foundation for their help.

Conflicts of Interest: The author declares no conflict of interest.

\section{References}

1. US Environmental Protection Agency (US EPA). Design Manual: Odor and Corrosion Control in Sanitary Sewerage Systems and Treatment Plants; EPA Press: Washington, DC, USA, 1985; pp. 1-85.

2. Pochwat, K.; Kida, M.; Ziembowicz, S.; Koszelnik, P. Odours in sewerage-A description of emissions and of technical abatement measures. Environments 2019, 6, 89. [CrossRef]

3. Sivret, E.C.; Wang, B.; Parcsi, G.; Stuetz, R.M. Prioritisation of odorants emitted from sewers using odour activity values. Water Res. 2016, 88, 308-321. [CrossRef] [PubMed]

4. Pandey, S.K.; Kim, K.H.; Kwon, E.E.; Kim, Y.H. Hazardous and odorous pollutants released from sewer manholes and stormwater catch basins in urban areas. Environ. Res. 2016, 146, 235-244. [CrossRef] [PubMed]

5. Wang, B.; Sivert, E.C.; Parcsi, G.; Wang, X.; Stuetz, R.M. Characterising volatile organic compounds from sewer emission by thermal desorption coupled with Gas-Chromatography-mass spectrometry. Chem. Eng. Trans. 2012, 30, 73-78. 
6. Frechen, F.B.; Romaker, J.; Giebel, S.M. Controlling chemical dosing into sewers for odour and corrosion abatement. Chem. Eng. Trans. 2014, 40, 217-222.

7. Liu, Y.; Ganigue, R.; Sharma, K.; Yuana, Z. Event-driven model predictive control of sewage pumping stations for sulfide mitigation in sewer networks. Water Res. 2016, 98, 376-383. [CrossRef]

8. Sun, J.; Pikaar, I.; Sharma, K.R.; Keller, J.; Yuan, Z. Feasibility of sulfide control in sewers by reuse of iron rich drinking water treatment sludge. Water Res. 2015, 71, 150-159. [CrossRef] [PubMed]

9. Rathnayake, D.; Sathasivan, A.; Kastl, G.; Bal-Krishna, K.C. Hydrogen sulphide control in sewers by catalysing the reaction with oxygen. Sci. Total Environ. 2019, 689, 1192-1200. [CrossRef] [PubMed]

10. Korea Ministry of Environments. Statics of Sewerage Works in Korea. 2018. Available online: https://www. hasudoinfo.or.kr/stat/statRefDetail.do\# (accessed on 10 April 2020).

11. Hayes, J.E.; Stevenson, R.J.; Stuetz, R.M. The impact of malodour on communities: A review of assessment techniques. Sci. Total Environ. 2014, 500, 395-407. [CrossRef]

12. Seoul City. Full-Scale Reduction Study of Odor Emitted from Sewer Facilities; Seoul City Hall Press: Seoul, Korea, 2010; pp. 35-83.

13. Park, S.J. Remote monitoring and real-time abatement of odor emitted from sewer using odor sensors, wireless communication technique and microbial deodorant. Glob. NEST J. 2018, 20, 646-653.

14. National Environmental Technology Information Center. Final Report of Advanced Odor Management in Korea; National Environmental Technology Information Center Press: Seoul, Korea, 2014.

15. Hanbit Car Center Blog. Famous Night-View of Seoul Metropolitan City. Available online: https://search.nav er.com/search.naver?sm=tab_hty.top\&where=image\&query= $\% \mathrm{EC} \% \mathrm{~B} 2 \% \mathrm{AD} \% \mathrm{EA} \% \mathrm{~B} 3 \% 84 \% \mathrm{EC} \% \mathrm{~B} 2 \% 9 \mathrm{C}$ +\%EA $\%$ B3 $\%$ B5 $\%$ EC $\% 9 B \% 90+\% E C \% 95 \% B C \% E A \% B 2 \% B D \&$ oquery $=\% E C \% B 2 \% A D \% E A \% B 3 \% 84 \% E C \%$ B2 $\% 9 \mathrm{C}+\% \mathrm{EA} \% \mathrm{~B} 3 \% \mathrm{~B} 5 \% \mathrm{EC} \% 9 \mathrm{~B} \% 90+\% \mathrm{ED} \% 8 \mathrm{C} \% 9 \mathrm{C} \% \mathrm{ED} \% 94 \% 8 \mathrm{C} \% \mathrm{~EB} \% \mathrm{~A} 0 \% 9 \mathrm{~B} \&$ tqi $=U Y$ ss $\% 2 \mathrm{FdprvN} 8 \mathrm{ss}$ Ab\%2FZgdssssssAd-301092\#imgId=blog114445776\%7C13\%7C220808067807_873028109\&vType=rollout (accessed on 22 June 2020).

16. ASTM International. Atmospheric Analysis Standards. Available online: https://www.astm.org/Standards/a tmospheric-analysis-standards.html (accessed on 29 May 2020).

17. US EPA. Method 16-Semi-Continuous Determination of Sulfur Emissions from Stationary Sources. Available online: https://19january2017snapshot.epa.gov/sites/production/files/2016-06/documents/m-16.pdf (accessed on 29 May 2020).

18. National Institute of Environmental Research. Standard Method for Odor Estimation and Analysis in Korea. Available online: https:/qaqc.nier.go.kr/qaqcnew/standard/standardlist.do (accessed on 29 May 2020).

19. Wu, C.; Liu, J.; Zhao, P.; Piringer, M.; Schauberger, G. Conversion of the chemical concentration of odorous mixtures into odour concentration and odour intensity: A comparison of methods. Atmos. Environ. 2016, 127, 283-292. [CrossRef]

20. Han, J.S.; Park, S.J. A study of the correlation between the concentration and dilution factor of sulfur compounds, $\mathrm{NH}_{3}$, and TMA. Korean J. Odor Res. Eng. 2012, 11, 87-93. [CrossRef]

21. Han, J.S.; Lim, Y.J.; Park, S.J. A study on the calculation methods of odor threshold values of the specified offensive odor substances. Korean J. Odor Res. Eng. 2012, 11, 24-33.

22. Nagata, N. Measurement of Odor Threshold by Triangle Odor Bag Method. Available online: https: //www.env.go.jp/en/air/odor/measure/02_3_2.pdf (accessed on 10 January 2019).

23. Leonardos, G.; Kendall, D.; Barnard, N. Odor Threshold Determinations of 53 Odorant Chemicals. J. Air Pollut. Control Assoc. 1969, 19, 91-95. [CrossRef]

24. Langford, S.V.; McEwan, J.M.; Askey, M.; Barnes, H.A.; Olerenshaw, J.G. Comprehensive instrumental odor analysis using SIFT-MS: A case study. Environments 2018, 5, 43. [CrossRef]

25. Dentoni, L.; Capelli, L.; Sironi, S.; Rosso, R.D.; Zanetti, S.; Torre, M.D. Development of an electronic nose for environmental odour monitoring. Sensors 2012, 12, 14363-14381. [CrossRef]

26. Brattoli, M.; Cisternino, E.; Dambruoso, P.R.; Gennaro, G.; Giungato, P.; Mazzone, A.; Palmisani, J.; Tutino, M. Gas chromatography analysis with olfactometric detection (GC-O) as a useful methodology for chemical characterization of odorous compounds. Sensors 2013, 13, 16759-16800. [CrossRef]

27. Yan, L.; Liu, J.; Jiang, S.; Wu, C.; Gao, K. The regular interaction pattern among odorants of the same type and its application in odor intensity assessment. Sensors 2017, 17, 1624. [CrossRef] 
28. Xu, Y.; Zhao, X.; Chen, Y.; Zhao, W. Research on a mixed gas recognition and concentration detection algorithm based on a metal oxide semiconductor olfactory system sensor array. Sensors 2018, 18, 3264. [CrossRef]

29. Wen, T.; Luo, D.; He, J.; Mei, K. The odor characterizations and reproductions in machine Olfactions: A review. Sensors 2018, 18, 2329. [CrossRef]

30. Wen, W.C.; Chou, T.I.; Tang, K.T. A Gas mixture prediction model based on the dynamic response of a metal-oxide sensor. Micromachines 2019, 10, 598. [CrossRef] [PubMed]

31. Damuchali, A.M.; Guo, H. Evaluation of a field olfactometer in odour concentration measurement. Biosyst. Eng. 2019, 187, 239-246. [CrossRef]

32. Pérez, A.O.; Frenes, V.K.; Filbert, A.; Kneer, J.; Bierer, B.; Held, P.; Klein, P.; Wöllenstein, J.; Benyoucef, D.; Kallfaß, S.; et al. Odor-sensing system to support social participation of people suffering from incontinence. Sensors 2017, 17, 58. [CrossRef] [PubMed]

33. Cipriano, D.; Capell, L. Evolution of electronic noses from research objects to engineered environmental odour monitoring systems: A review of standardization approaches. Biosensors 2019, 9, 75. [CrossRef] [PubMed]

34. Han, J.S.; Park, S.J. A study of the correlation between the odor intensity and dilution factor of NH3, TMA and styrene. Korean J. Odor Res. Eng. 2010, 9, 196-202.

35. Japan Association on Odor Environment. Chapter 3 Correlation Equation between Odor Intensity and Odor Compounds Concentration-Handbook of Odor Prevention Law, 6th ed.; Gyosei Digital Press: Tokyo, Japan, 2012; Volume 2.

(C) 2020 by the author. Licensee MDPI, Basel, Switzerland. This article is an open access article distributed under the terms and conditions of the Creative Commons Attribution (CC BY) license (http://creativecommons.org/licenses/by/4.0/). 